\title{
The College Students' Mental Health Analysis and Application Based on Fuzzy Comprehensive Evaluation
}

\author{
PANG Yang ${ }^{1, \text { a }}$, YUAN Hui ${ }^{2}$ and WANG Xiaoyan ${ }^{3}$ \\ ${ }^{1}$ Qingdao Vocational and Technical College of Hotel Management, Qingdao 266100,China \\ ${ }^{2}$ Ocean University of China, Qingdao 266100,China \\ ${ }^{3}$ Shandong University of Arts, jinan 250300, China \\ aPangYang1020@yeah.net
}

Keywords: student membership degree; fuzzy comprehensive evaluation; quality; Higher Vocational Colleges; study;

\begin{abstract}
College Students' mental health education has been a hot issue in current education, mental health education of college students is to provide a comparison of the platform, based on national laws and regulations and survey analysis, operational evaluation index system of psychological health education of college students is established, to determine the current mental health education guarantee system College students' psychological health education, the implementation effect evaluation of mental health education evaluation content, evaluation criteria, and the education management system, evaluation of psychological education, psychological education effect evaluation test evaluation indicators, and using AHP to determine the weight of each level of evaluation index, establishes the multi-level fuzzy comprehensive evaluation model. Finally, apply this evaluation system of a university; verify the feasibility and rationality of the index system.
\end{abstract}

\section{Introduction}

Based on the analysis of various factors of College Students' comprehensive quality, people set up an evaluation index system of College Students' comprehensive quality and multi hierarchical comprehensive evaluation model; we can judge the comprehensive quality of a university undergraduate college students according to related surveys and statistical data, so that it is concluded that the students' overall quality are in a good level. [3]Scientific and reasonable, objective and impartial evaluations of the quality of higher vocational college students are facing with important problems by comprehensively promote quality education. According to the characteristics of vocational students will factors of students' quality as moral, intellectual, physical, occupational skills, interpersonal communication and innovation are in six aspects, based on establishing the comprehensive quality of college students on the evaluation system, establishing the mathematical model using the fuzzy comprehensive evaluation method, and then through the analysis of examples to verify the feasibility of the model. This model not only has the identification, diagnosis and ranking function, also has the function of guidance and motivation.

\section{The establishment of College Students' comprehensive quality evaluation index system}

The establishment of evaluation index system should conform to the comprehensive, independent, and capable of observing the three principles (see Fig 1). [2] 


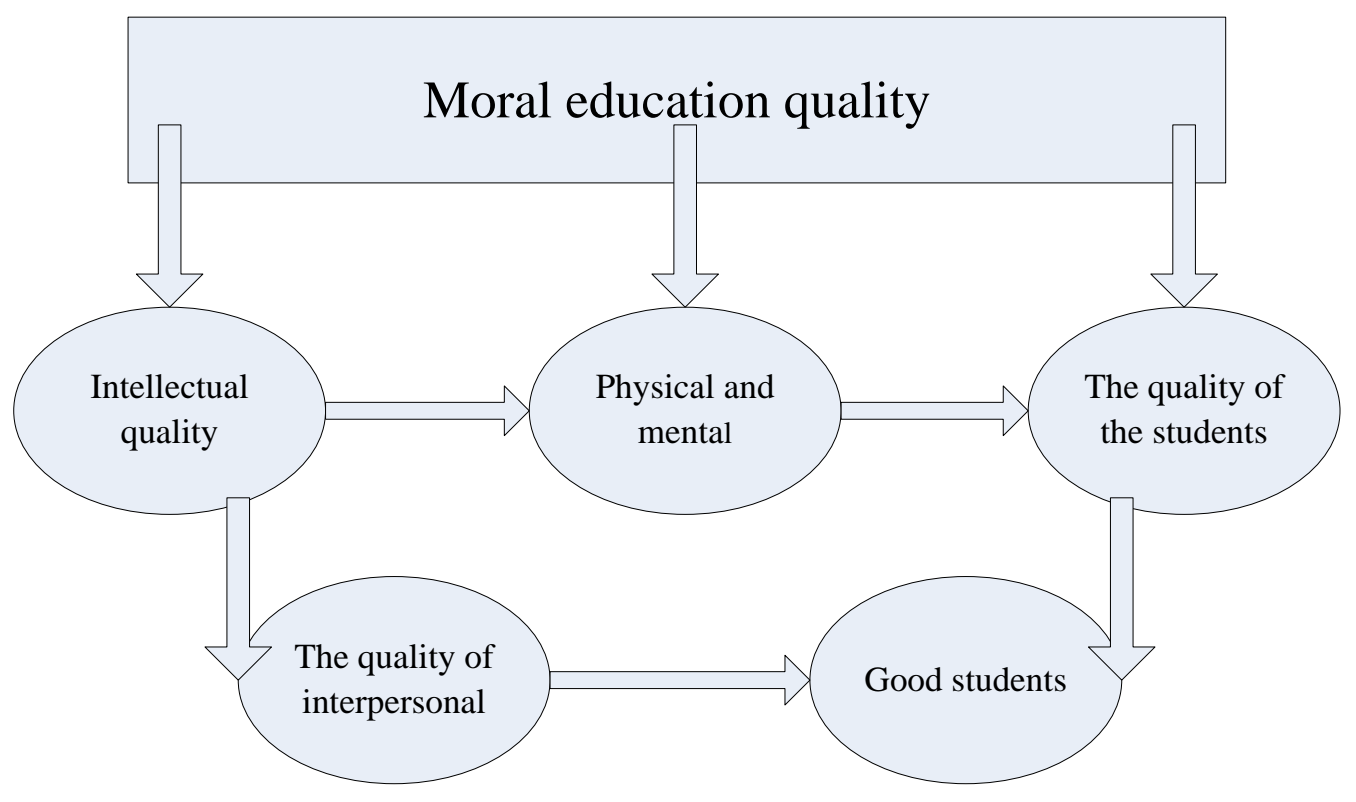

Fig 1 Capable of observing the three principles

(1) Moral education quality. According to the Chinese ordinary higher school moral education program and the program for improving civic morality, require students to support the leadership of the party, maintain the unity of the country, is committed to realizing the fundamental interests of the broad masses of the people; and gradually form a good moral consciousness, speech and deportment civilization, the pursuit of moral behavior of high still, abide by the occupation ethics;

(2) Intellectual quality. Learning ability is shown in the basic activities of observation, memory, abstract generalization ability, attention, comprehension, it has a direct impact on the learning achievement but not equal to learning achievement;

(3) Physical and mental quality. Including physical education achievement; by the basic qualities of body shape and function, strength, explosive force indexes, athletic ability, sensitive and coordination composition; mental health can be investigated by the aspects of intelligence and emotion.

(4) The quality of the professional skills. Teach high No. 16 document made clear that the higher vocational education is to cultivate high-quality skilled talents, this index is the significant characteristics of vocational distinguished from ordinary undergraduate course, the study points including vocational skills course; vocational qualification certificate; vocational skills competition awards etc...

(5) The quality of interpersonal communication. Many higher vocational graduates are deeply interpersonal communication difficulties in employment, appeared on the surface of interpersonal communication is born, can not be changed, in fact, interpersonal communication is can be improved by learning. The study points including communication skills; served as caucus position, students, class, community management, assistant head teacher and other social work.

Using the fuzzy comprehensive evaluation method, first to determine the weight of each factor needs, it is related to the degree of reliability assessment results, can adopt the experience method, Delphi method (Delphi Method), analytic hierarchy process (AHP), fuzzy analytic hierarchy process (FAHP), due to the limited space. [2]

\section{Higher Vocational fuzzy comprehensive evaluation model based on the evaluation of students' quality}

The establishment of a set of factors (index set): one class index $=\{,,,\}=,\{$ moral quality, intellectual quality, physical and psychological quality, occupation skill quality, interpersonal communication quality, innovation quality $\}$. Two indicators of moral quality $=\{,,\}=$, ppolitical consciousness, moral character, concept of rule of law, occupation moral $\}$, intellectual quality $=\{,$, $=\{$ learning ability, learning achievement, University English level $\}$, physical and mental quality $=$ 
$\{,\}=$, the physical quality, mental health, health habits $\}$ occupation, skill quality $=\{,$, achievement occupation skill course $=\{$, occupation qualification certificate, occupation skill contest $\}$, interpersonal communication quality $=\{\}=,\{$ communication ability, as a social work $\}$, innovation quality $=\{\}=,\{$ innovation ability, innovation contest $\}$.[1]

(1) The establishment of comment sets: $=\{,$, , excellent, good, medium, pass, fail $\}$.

(2) To determine the fuzzy evaluation matrix: The element $([0,1])$ is for the membership factor about comments. Determining the membership by some experts (counselor, teacher, teacher, and student representatives) consisted of the assessment team conducted a questionnaire survey.

(3) Single level fuzzy comprehensive evaluation. The first of the 6 first level indicators of moral quality, intellectual quality, physical and psychological quality, occupation skill quality, interpersonal communication quality, innovation quality were two level fuzzy evaluations. Now with the moral quality $=\{,,\}=$, political consciousness, moral character, concept of rule of law, occupation moral $\}$ as an example, through the questionnaire survey to get $\{,$,$\} , respectively on \{,,,$, to get the degree of membership, fuzzy evaluation matrix: Similarly available on the intellectual quality, physical and psychological quality, occupation skill quality, interpersonal communication quality, innovation quality single level fuzzy comprehensive evaluation results were $==(,,),) . . .=$ $(,,,$,$) . [1]$

As a final result of fuzzy comprehensive evaluation, it is based on the principle of maximum degree of membership can determine the evaluation grade.

\section{The example analysis}

The establishment of a counselor, teacher, teacher, student representatives assessment team randomly selected students, through a questionnaire survey to members of the assessment team, get each of the students two grade indexes about the various comments membership (grades including competition results, College English classes, vocational qualification certificate is hard the index, can be credited to the appropriate level, directly according to certain criteria as social work according to duty height recorded in the corresponding level). [4]

\section{Conclusion}

Although the model built for college students, as long as the proper adjustment of the index system, but also it is for ordinary colleges and universities because of its simple principle: stable model. It is easy to develop students' comprehensive quality evaluation system of computer, to help us complete the evaluation process, this kind of operation process of human factors, less interference, a comparatively objective evaluation therefore, identification, diagnosis and ranking has better effect. At the same time, judge is step by step, can clearly see the student's good aspects and deficiencies, which are convenient for students to understand the self, but also provide a direction for the relevant administrative department for individual counseling. In the model, the weight vector is given to us, therefore, different schools or different period, need to be flexible and adjust the weight vector, the evaluation indexes of different, therefore the model is both guide and encourage the function.

College Students' comprehensive quality assessment is an appraisal of students' work in Colleges and universities every year, the colleges and universities is an urgent need to solve the problems for designing a set of scientific, reasonable, feasible evaluation of comprehensive quality standards, establishing a convenient, efficient, and adapting to the new situation of the students comprehensive quality evaluation system. Characteristics and evaluation methods are showed in this paper based on analyzing the existing students comprehensive quality evaluation system on the advantages and disadvantages, this paper uses analytic hierarchy process to establish the evaluation index and design the index system, which has formulated a set of reasonable and feasible evaluation index system. Evaluation of comprehensive quality of students is complex evaluations process a multifactor and multi index, not simply good and bad to distinguish. Fuzzy logic is anaccurate method to solve the imprecise incomplete information, fuzzy and its greatest feature is used which 
can be compared with natural treatment of human thinking. This paper calculates using fuzzy comprehensive evaluation method to evaluate data, scientific and accurate assurance assessment results. UML is a modeling langugage which includes new theory, new method and newtechnology of software engineering fields. Therefore the system requirements analysis, and it is great important to develop and implement a comprehensive quality evaluation system of Collegestudents.

\section{References}

[1] Du Junying, Research on the system and content [J], College counselor of university students' overall quality evaluation, 2011 (2):14.

[2] fan Chunli, A comprehensive evaluation of College [J], System in Higher Education Development and Assessment, 2010 (9):19.

[3] Wu Yongjin, a Minggang, Construction of Ideological and political education research [J]. Thinking training system of the comprehensive quality of students, 2009 (08):44-47

[4] Xian Yuanying, Yin Dezhi, Analysis of College Students' comprehensive quality level evaluation system and mathematical model [J]. Journal of Southwest University for Nationalities, 2002(02):22-26.

[5] Zeng huaxi, Journal of evaluation of comprehensive quality of college student's fuzzy comprehensive evaluation method based on the [J], Jilin business school, 2001 (05):62-65. 